\title{
Stiffness characteristics and thermal deformations of the frame of high power marine engine
}

\author{
Lech Murawski \\ Marek Szmyt \\ Centrum Techniki Okrętowej S. A. (CTO) \\ (Ship Design and Research Centre)
}

\section{ABSTRACT}

\begin{abstract}
In the subject-matter literature detail data on stiffness of the crankshaft foundation connected with the frame of marine main engine are still lacking. Thermal deformation models of the engine's casing, proposed by engine producers, are excessively simplified. However the parameters are crucial for the shaft-line alignment analysis as well as for the analysis of interactions between the shaft-line and engine crankshaft, especially in the case of high power engines. This paper presents a determination method of the marine engine body characteristics as well as results of example computations performed for a Sulzer 7 RTA 84 C engine installed on a 3000 TEU container ship. It has been demonstrated that the producer's assumption about parallel displacement of the crankshaft axis in thermal working conditions is too rough. The thermal deformation of the engine is of hogging character, which results in significant change of the moment load exerted on the crankshaft and shaft line. The stiffness parameters recommended by the producers for the shaft-line alignment are estimated correctly, however they represent only engine's body flexibility, without taking into account ship's hull flexibility.
\end{abstract}

Keywords : marine main engine, main bearing, static and dynamic stiffness characteristics of bearing, thermal deformation, temperature distribution

\section{INTRODUCTION}

The aim of the presented work has been to evaluate displacements of the engine crankshaft axis in different working conditions of propulsion system $[3,5]$. In the shaft-line alignment methods the crankshaft-shaft line interaction has been considered in a simplified way so far. The crankshaft has been modelled as a linear system of cylindrical beam elements, whereas its thermal displacements and its foundation stiffness have been evaluated on the basis of simple data supplied by the producer without considering the type of the ship on which the engine has to be installed [4]. The goal of the work has been to improve representation of the boundary conditions of the marine power transmission system. It is especially important for the high power propulsion systems since in the literature many examples of the damage of the first three main bearings (counting from the driving end) of the main engine can be found $[1,2]$. One of the possible causes of such state might be the imprecise mathematical model of crankshaft, proposed for the analysis of shaft line alignment.

Within the frame of this work several analyses of the Sulzer 7 RTA $84 \mathrm{C}$ engine installed on a big container ship (of $\sim 3000$ TEU capacity) were carried out. Also, the computation of engine body deformation under gravity load as well as the analysis of its thermal deformation in nominal working conditions was performed. The static stiffness (horizontal and vertical) of each of the main bearings were evaluated and then their dynamic stiffness was determined in the frequency range of $0 \div 30 \mathrm{~Hz}$. As the forced vibration analysis was performed with the use of the modal superposition method, it was necessary to determine in advance the natural frequencies and eigenvalues in the frequency range of $0 \div 70 \mathrm{~Hz}$. The thermal analysis requires an accurate temperature distribution on the engine body to be known. Appropriate data were obtained from comprehensive temperature measurements performed on the ship and her main engine.

\section{ANALYSIS METHOD}

The FEM model of the body of Sulzer 7 RTA 84 C engine is presented in Fig.1. Fig.2 shows a part of the model representing the engine main bearing. The engine body model contains almost 200 thousand plate and solid elements of over 930 thousand degrees of freedom.

The subject of the analysis was the body of Sulzer 7 RTA 84 C engine. The analysis involved, apart from heat flow, also thermal deformation and stress calculated by means of a 3D heat transfer model. The method is based on the solution of the heat flow equation (with variable coefficients). For stationary heat flow the equation has the following form:

$$
\begin{gathered}
\frac{\partial}{\partial \mathrm{x}}\left[\mathrm{k}(\mathrm{x}, \mathrm{y}, \mathrm{z}) \frac{\partial \mathrm{T}}{\partial \mathrm{x}}\right]+\frac{\partial}{\partial \mathrm{y}}\left[\mathrm{k}(\mathrm{x}, \mathrm{y}, \mathrm{z}) \frac{\partial \mathrm{T}}{\partial \mathrm{y}}\right]+ \\
+\frac{\partial}{\partial \mathrm{z}}\left[\mathrm{k}(\mathrm{x}, \mathrm{y}, \mathrm{z}) \frac{\partial \mathrm{T}}{\partial \mathrm{z}}\right]=0
\end{gathered}
$$

If the convective boundary conditions on both hot and cold surface are assumed then the following relations are valid :

$$
\begin{aligned}
& -\mathrm{k}(\mathrm{x}, \mathrm{y}, \mathrm{z}) \frac{\partial \mathrm{T}}{\partial \mathrm{y}}=\mathrm{h}\left(\mathrm{T}_{\mathrm{s}}-\mathrm{T}_{\mathrm{a}}\right) \\
& -\mathrm{k}(\mathrm{x}, \mathrm{y}, \mathrm{z}) \frac{\partial \mathrm{T}}{\partial \mathrm{z}}=\mathrm{h}\left(\mathrm{T}_{\mathrm{s}}-\mathrm{T}_{\mathrm{a}}\right)
\end{aligned}
$$




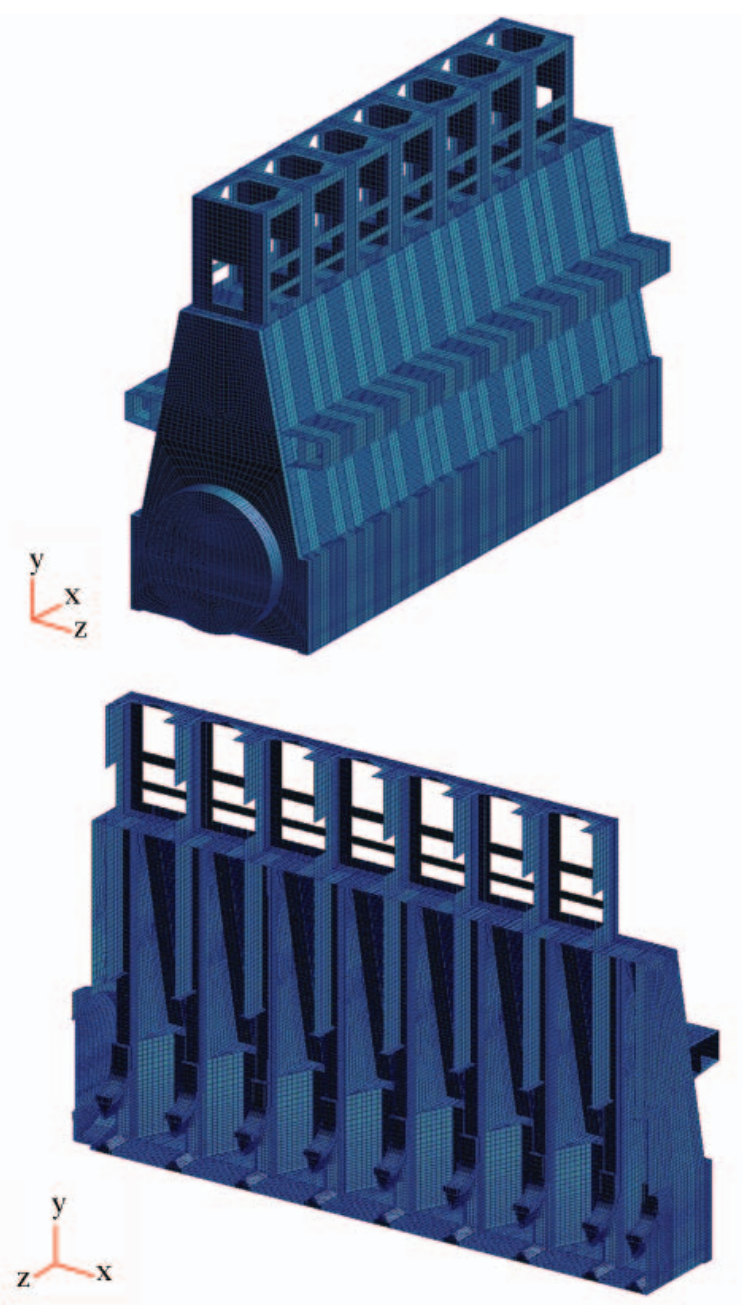

Fig. 1. FEM model of Sulzer 7 RTA 84 C engine.

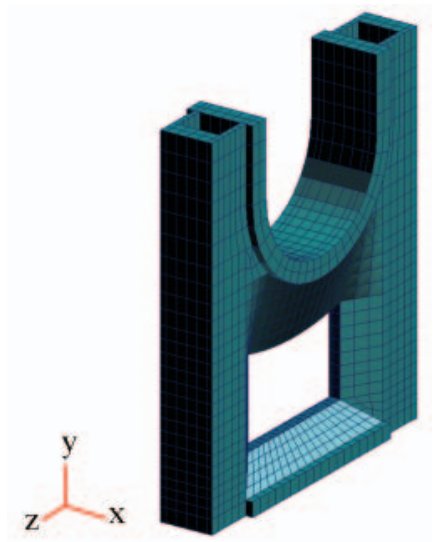

Fig. 2. Main bearing frame of Sulzer 7 RTA 84 C engine

No heat flow is assumed on other surfaces of boundary planes of the considered hull segment, which leads to the equation:

$$
\frac{\partial \mathrm{T}}{\partial \mathrm{x}}=0
$$

The FEM thermal analysis was performed with the use of MSC NASTRAN software. MSC PATRAN software was used as a pre-and post-processor for the calculation results of the stress under thermal load.

Before starting the thermal deformation analysis of the engine it is necessary to determine temperature distribution on its body. The temperature map was created on the basis of the measurements carried out on a marine main whose size and structure was similar to those of the engine in question.

\section{TEMPERATURE DISTRIBUTION MEASUREMENT ON ENGINE BODY}

The temperature distribution measurements on the engine body were performed on the Sulzer 8 RTA 96 C engine during sea trials. The engine load was kept stable in nominal working conditions. Alfa-Tech Rytek MT 4 pyrometer was used for the measurements. The example layout of measurement points (on the port side) is shown in Fig.3. The results of measurements in those points are presented in Tab.1. On the starboard side as well as on the fore and aft end of the engine the measurement points were distributed in a similar way.

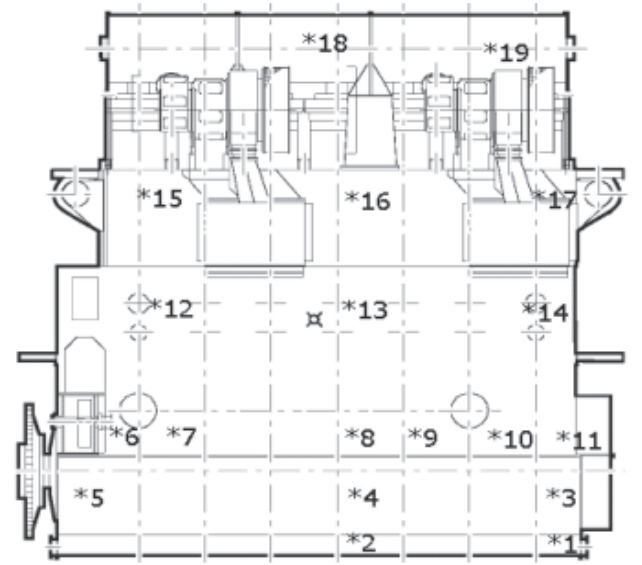

Fig. 3. Layout of the measurement points on the port side of the main engine body.

Tab. 1. Results of the temperature measurements performed on the port side of the main engine body.

\begin{tabular}{|c|c|c|c|c|c|}
\hline \multicolumn{6}{|c|}{ Port side of the Engine } \\
\hline $\begin{array}{c}\text { Measure- } \\
\text { ment } \\
\text { point No. }\end{array}$ & $\begin{array}{c}\text { Measured } \\
\text { tempera- } \\
\text { ture }\left[{ }^{\circ} \mathbf{C} \text { ] }\right.\end{array}$ & $\begin{array}{c}\text { Measure- } \\
\text { ment } \\
\text { point No. }\end{array}$ & $\begin{array}{c}\text { Measured } \\
\text { tempera- } \\
\text { ture }\left[{ }^{\circ} \mathbf{C}\right]\end{array}$ & $\begin{array}{c}\text { Measure- } \\
\text { ment } \\
\text { point No. }\end{array}$ & $\begin{array}{c}\text { Measured } \\
\text { tempera- } \\
\text { ture }\left[{ }^{\circ} \mathbf{C} \text { ] }\right.\end{array}$ \\
\hline 1 & 37 & 8 & 52 & 15 & 51 \\
\hline 2 & 44 & 9 & 49 & 16 & 50 \\
\hline 3 & 52 & 10 & 52 & 17 & 57 \\
\hline 4 & 53 & 11 & 49 & 18 & 60 \\
\hline 5 & 54 & 12 & 50 & 19 & 63 \\
\hline 6 & 49 & 13 & 54 & & \\
\hline 7 & 53 & 14 & 54 & & \\
\hline
\end{tabular}

THERMAL ANALYSIS OF ENGINE BODY DEFORMATION

In the numerical thermal analysis the value of heat conductivity coefficient for steel was assumed equal to 42.9 [W/m K]. The heat flow analysis was performed for the condition of the hold being hot and thermally balanced. Because of lack of more precise data the heat transfer coefficients were assumed as for heated cargo in accordance with DNV Classification Rules. The values of heat transfer coefficients are presented in Tab.2. The thermal expansion coefficient of the engine body was assumed equal to $\alpha=1.6 \times 10^{-5}$. The temperature distribution on the engine body, shown (in ${ }^{\circ} \mathrm{C}$ ) in Fig.4, was analogous to that obtained from the measurements.

Tab. 2. Assumed values of heat transfer coefficients $\left[\mathrm{W} / \mathrm{m}^{2}{ }^{\circ} \mathrm{C}\right]$.

\begin{tabular}{|c|c|}
\hline From air in the hold to the inner bottom structure & 58.1 \\
\hline From air in the hold to the side structure & 58.1 \\
\hline From air in the hold to the deck structure & 58.1 \\
\hline From outboard water to the hull shell & 7400 \\
\hline From air to the hull shell & 23.2 \\
\hline From air in the double bottom to the hull structure & 0 \\
\hline
\end{tabular}



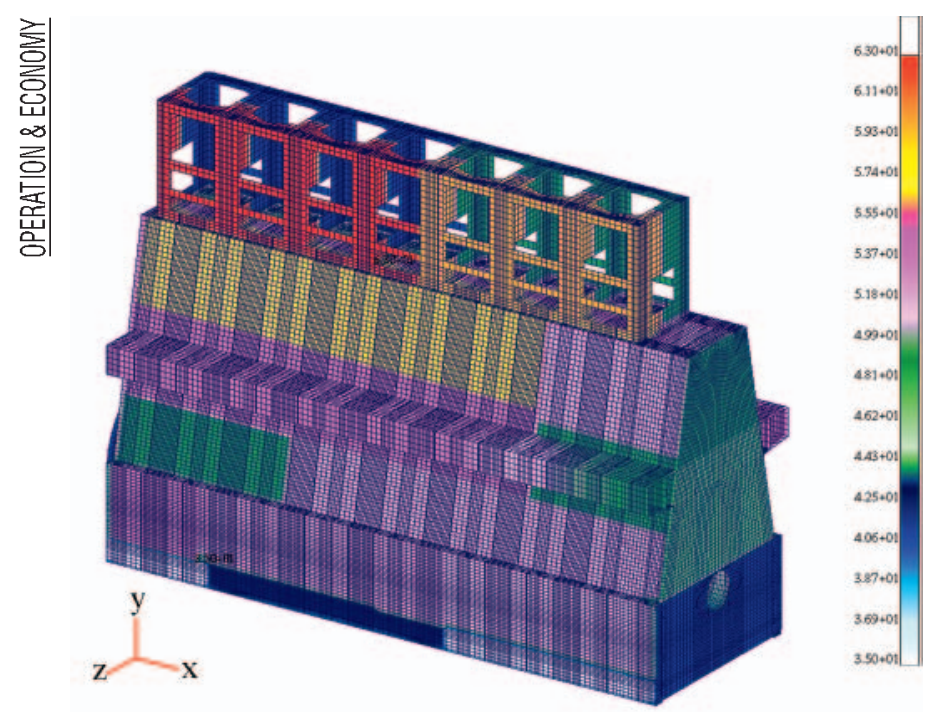

Tab.3. Thermal displacements of the main bearings of Sulzer 7 RTA 84 C engine.

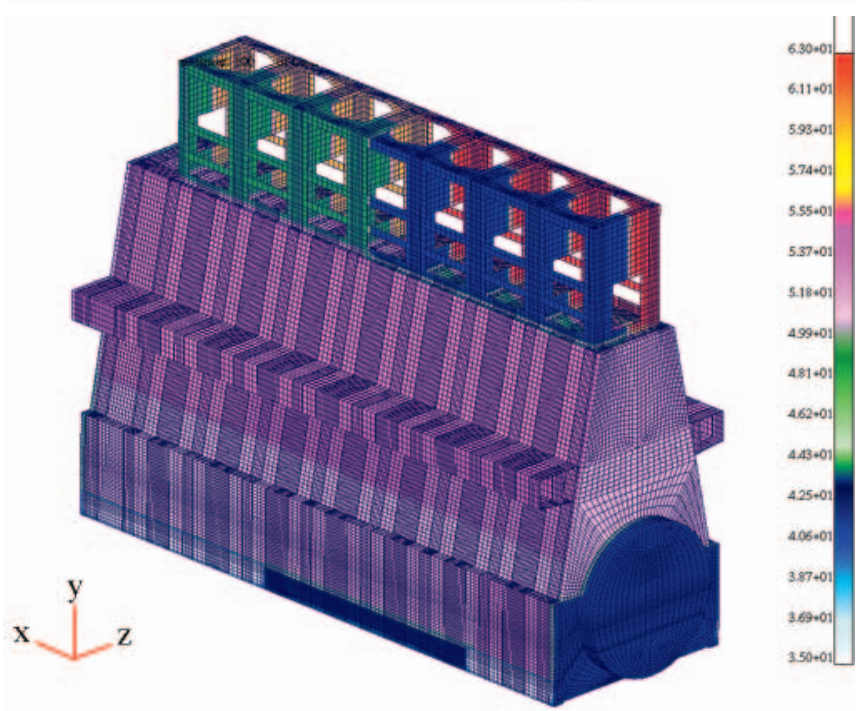

Fig. 4. Temperature distribution on the engine body, assumed for the analysis. Note: On this and all next figures the SI standard units (e.g. $m, P a)$ are applied .

In Fig. 5 the thermal deformation of the engine body is presented in the form of fringe plot. From the point of view of the propulsion system and main engine - shaft line interaction, displacements of the engine main bearings are most important. The values of the displacements are presented in Tab.3. The bearings are numbered beginning from the driving end of the shaft line (the right-hand side of Fig.5).
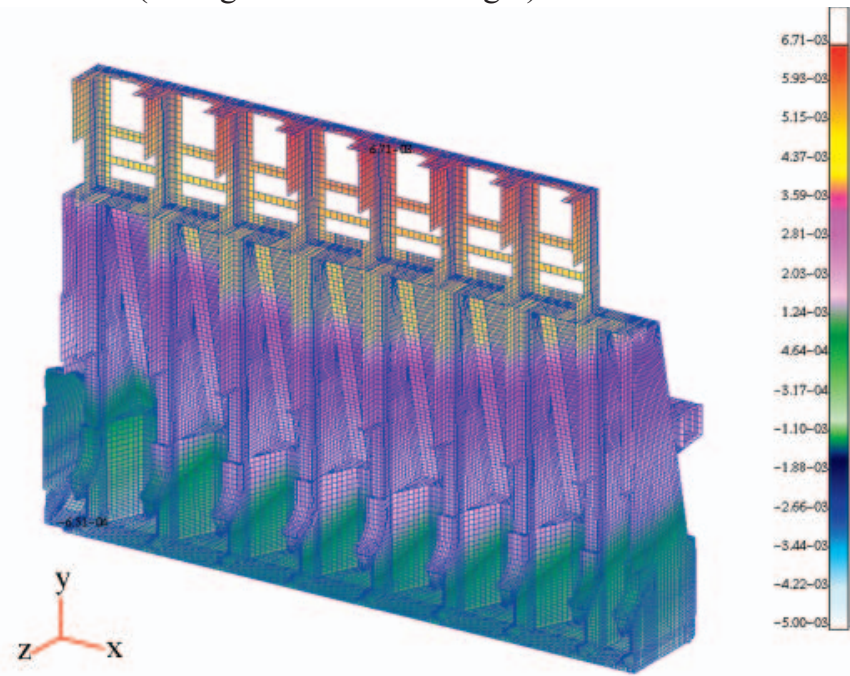

Fig. 5. Thermal deformation of the body of Sulzer 7 RTA 84 C engine

\begin{tabular}{|c|c|c|c|}
\hline $\begin{array}{c}\text { Main bearing } \\
\text { No. }\end{array}$ & $\begin{array}{c}\text { Vertical } \\
\text { displacement } \\
{[\mathbf{m m}]}\end{array}$ & $\begin{array}{c}\text { Horizontal } \\
\text { displacement } \\
{[\mathbf{m m}]}\end{array}$ & $\begin{array}{c}\text { Axial } \\
\text { displacement } \\
{[\mathbf{m m}]}\end{array}$ \\
\hline 1 & 0.756 & -0.004 & 1.905 \\
\hline 2 & 1.086 & -0.001 & 1.327 \\
\hline 3 & 1.428 & 0.002 & 0.604 \\
\hline 4 & 1.564 & 0.005 & 0.290 \\
\hline 5 & 1.627 & 0.009 & 0.056 \\
\hline 6 & 1.605 & 0.011 & -0.180 \\
\hline 7 & 1.498 & 0.010 & -0.476 \\
\hline 8 & 1.252 & 0.006 & -0.948 \\
\hline 9 & 0.645 & -0.005 & -1.986 \\
\hline
\end{tabular}

For the crankshaft axis translation the main engine's producer recommends to use the following formula :

$$
\mathrm{h}_{\mathrm{e}}=\mathrm{dh}\left(\mathrm{T}_{\mathrm{s}}-\mathrm{T}_{\mathrm{a}}\right)
$$

where :

$h_{e}-$ displacement of the main bearing axis [mm]

$\mathrm{dh}$ - thermal expansion coefficient of the engine body $[\mathrm{mm} / \mathrm{K}]$

$\mathrm{T}_{\mathrm{s}}-$ service temperature of the engine $[\mathrm{K}]$

$\mathrm{T}_{\mathrm{a}}$ - air temperature in the engine room $[\mathrm{K}]$.

For the examined Sulzer 7 RTA $84 \mathrm{C}$ engine the translation of the main bearing axis amounts to :

$$
\mathrm{h}_{\mathrm{e}}=18.4 \cdot 10^{-3}(53.0-20)=0.607 \mathrm{~mm}
$$

The numerically computed value of the translation of the shaft line axis (Tab. 3) is greater than that recommended by the producer despite the fact that the measured temperature of the real engine is slightly lower than its specified service temperature. The difference for the first bearing is not particularly large (less than 20\%), but other bearings are much more displaced. It seems that the producer's assumption on the parallel translation of the crankshaft axis is incorrect. The hogging deformation of the crankshaft results in a significant change of the moment transferred from the shaft line. Its effect calculated by using a precise shaft line alignment analysis would be considerable.

\section{ANALYSIS OF STATIC STIFFNESS OF MAIN BEARINGS OF THE ENGINE}

Determination of the static stiffness consists in applying unitary forces equal to mass forces and radial gas forces (of $750 \mathrm{kN}$ ), to each of the main bearings, one by one, first in vertical and then in horizontal direction. The achieved displacements serve to calculate the local static stiffness. The quantities are very important for shaft line alignment analysis since applying only the ship's hull stiffness may be insufficient. The main engine producers usually provide (on request) information on the crankshaft foundation stiffness but without dividing the quantity into that concerning engine body alone and ship hull. Some time ago this parameter was assumed infinitely large, now it is considered as large as $6.0 \times 10^{9} \mathrm{~N} / \mathrm{m}$. The CTO Co. gained vast experience concerning the stiffness of ship hulls of many types but no main engine body stiffness has been so far examined by this company.

The deformation of the main engine body under only gravity load was computed first. It was observed that the deformation due to gravity load was several times smaller (of the order of only $0.01 \mathrm{~mm}$ ) than that due to thermal load, cylinder mass and 
gas forces. Therefore in further analysis the influence of gravity load may be neglected.

Next, was carried out the static analysis consisting in application of the load first in vertical and then in horizontal direction (18 load cases). The estimated radial forces were distributed on the main bearing surface. Tab. 4 contains the static stiffness values for particular main bearings (numbered beginning from the aft - driving end of the crankshaft). The selected deformation values and stress fringe plots are presented in Fig. $6 \div 8$.

Tab. 4. Static stiffness of the main bearings of Sulzer 7 RTA 84 C engine.

\begin{tabular}{|c|c|c|}
\hline Main bearing No. & $\begin{array}{c}\text { Vertical stiffness } \\
\times 10^{9}[\mathrm{~N} / \mathrm{m}]\end{array}$ & $\begin{array}{c}\text { Horizontal stiffness } \\
\times 10^{9}[\mathrm{~N} / \mathrm{m}]\end{array}$ \\
\hline 1 & 6.615 & 10.942 \\
\hline 2 & 6.828 & 11.232 \\
\hline 3 & 7.317 & 12.229 \\
\hline 4 & 7.357 & 12.300 \\
\hline 5 & 7.364 & 12.325 \\
\hline 6 & 7.360 & 12.307 \\
\hline 7 & 7.329 & 12.248 \\
\hline 8 & 7.188 & 12.020 \\
\hline 9 & 6.312 & 9.689 \\
\hline
\end{tabular}

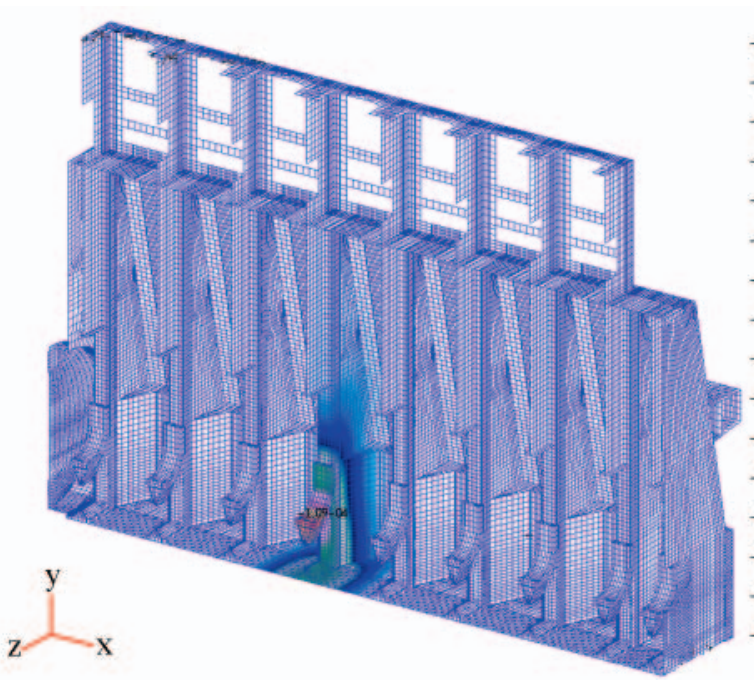

Fig. 6. Deformation of the main engine body under vertical load applied to $6^{\text {th }}$ main bearing.

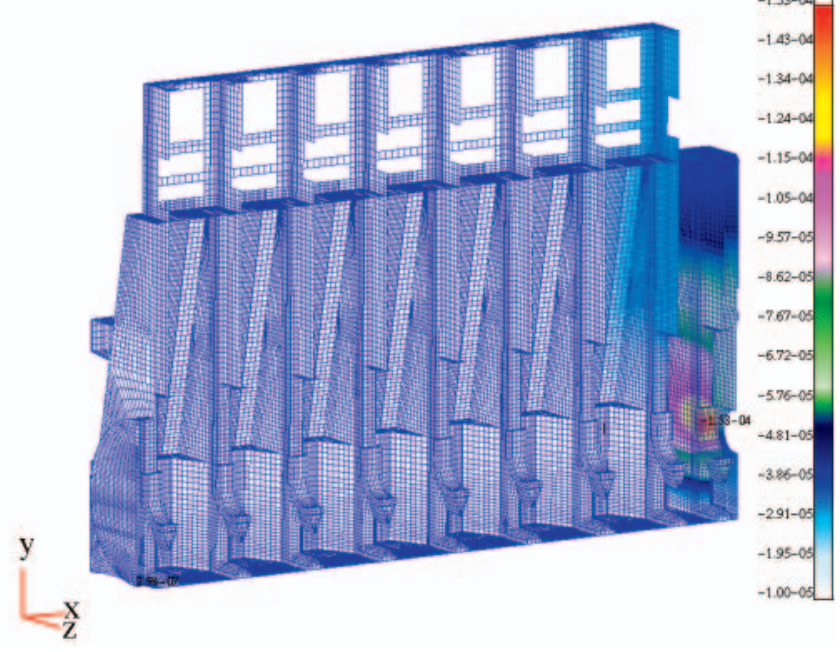

Fig. 7. Deformation of the main engine body under horizontal load applied to $1^{\text {st }}$ main bearing .
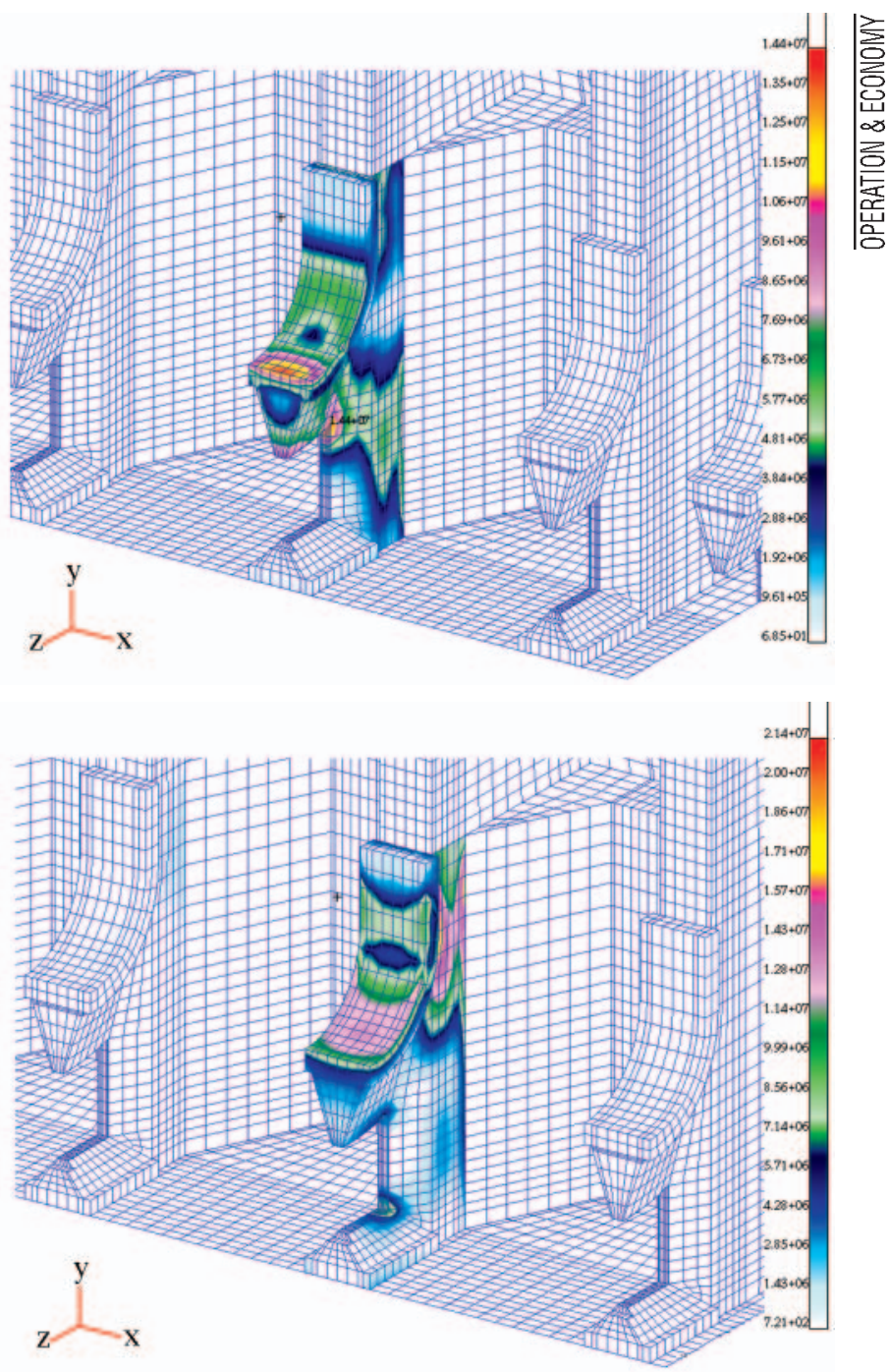

Fig. 8. Stress in the main engine body under vertical and horizontal load applied to $3^{\text {rd }}$ main bearing .

On the basis of the performed analysis it can be stated that the static stiffness values specified by the producer are properly evaluated, however they represent only the flexibility of the engine body without taking into account the ship hull flexibility. In the authors' opinion in the analysis of shaft line alignment the sum of both flexibility parameters should be taken into account. It can be observed that the engine body stiffness is very high and the cylinder mass and gas forces acting on a single cylinder have a little influence on displacements of other main bearings.

It means that it is not required to take into account any coupling between particular bearings - hence there is no necessity to determine the equivalent stiffness reflecting the engine structure integrity. It is intriguing that the horizontal stiffnesses are higher than the vertical ones, not so as in the case of most other marine structures. The stress level in the main bearing structure is not high as it does not exceed $15 \mathrm{MPa}$ for horizontal load and $22 \mathrm{MPa}$ for vertical one.

\section{ANALYSIS OF DYNAMIC STIFFNESS CHARACTERISTICS OF BEARINGS}

The determination of the dynamic stiffness characteristics consists in applying unitary forces defined as a function of excitation frequency, to each of the main bearings, one by one, first in vertical and then in horizontal direction. The obtained displacements serve to calculate the local dynamic stiffness for 
each excitation frequency, independently. These quantities are important for shaft line lateral vibration analysis. The data on the dynamic stiffness of main engine body are not available neither from literature nor from the producers.

The analysis of the dynamic stiffness of Sulzer 7 RTA 84 C engine body was carried out by using the MSC Nastran FEM solver and modal superposition method. The stiffness characteristics were determined in the frequency range of $0 \div 30 \mathrm{~Hz}$; this way the full spectrum of possible propulsion system excitation frequencies was covered. In such case according to the authors' experience, it is recommended to calculate normal modes in the range of natural frequency, taken at least twice as wide as that. The eigenmodes were determined for frequency values up to $70 \mathrm{~Hz}$. The eigenvector maps for the most important normal modes are shown in Fig. 9 $\div 11$. The applied denotation for engine body deformations, commonly used by engine producers, is as follows: $\mathbf{H}$ - lateral deformation, $\mathbf{X}$ - twisting deformation, $\mathbf{C}$ - bending deformation in vertical plane.

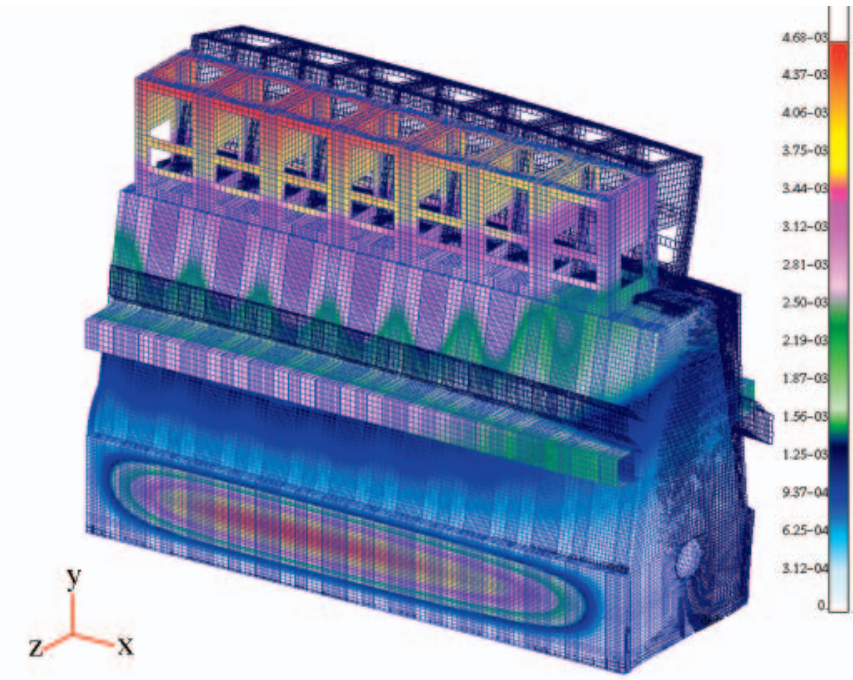

Fig. 9. "H"- type normal mode at the natural frequency of $32.90 \mathrm{~Hz}$

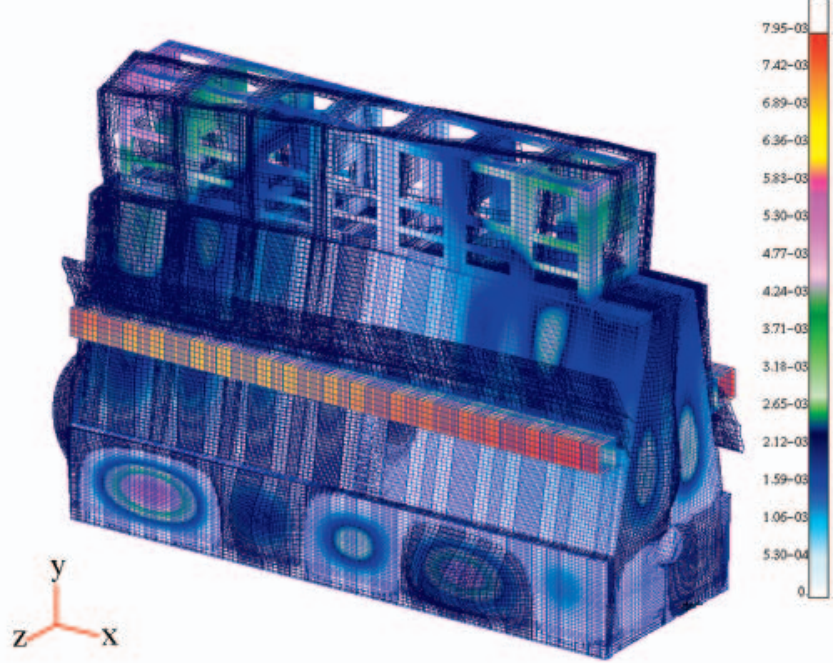

Fig. 10. "X"- type normal mode at the natural frequency of $45.30 \mathrm{~Hz}$

It is important that the first significant normal modes have their natural frequencies above the range of excitation frequencies of the propulsion system. And, the significant normal modes are only a few and those of interest concern the whole engine body. No significant normal modes were found in the region of the engine main bearings. It speaks well for the correct design of the engine body, i.e. of sufficiently rigid structure. In such case the resonance discontinuities of main bearing

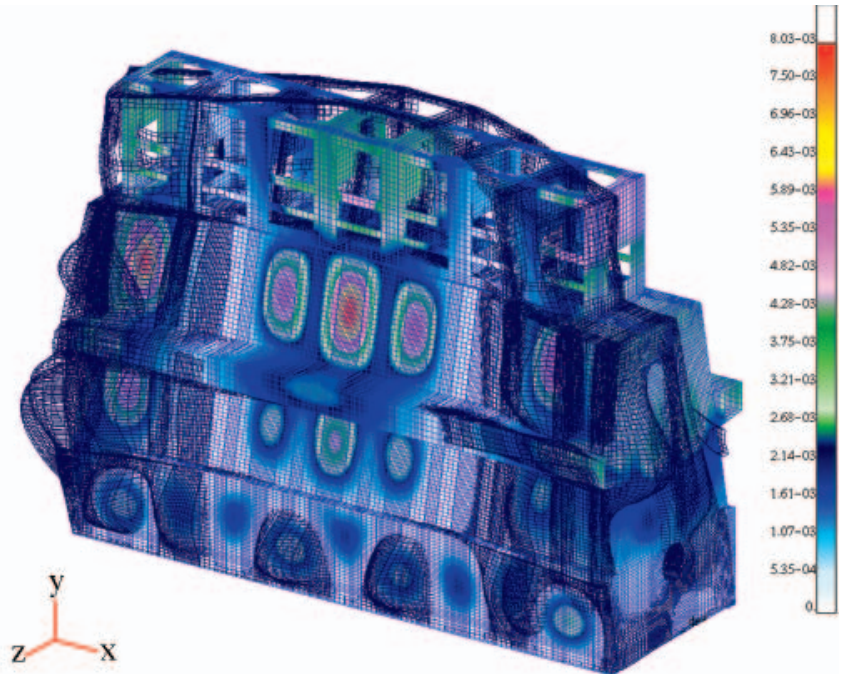

Fig. 11. "C"- type normal mode at the natural frequency of $69.95 \mathrm{~Hz}$

flexibility are not expected and the characteristics appear close to linear. For this type of structure it is allowed to use only static stiffness as the expected dynamic amplification should be insignificant.

Next step was to compute forced vibration by applying first vertical load and then horizontal one to each of the engine main bearings, one by one (18 load cases). The analysis was performed within the frequency range of $0 \div 30 \mathrm{~Hz}$. Tab.5 and 6 contain dynamic stiffness values for characteristic excitation frequencies and particular bearings (numbered beginning from the aft - driving end of the crankshaft). The nominal rotational speed of the examined engine was $100 \mathrm{rpm}$. The engine had seven cylinders, and the propeller - five blades. For such configuration the basic excitation frequencies were $8.33 \mathrm{~Hz}$ and $11.67 \mathrm{~Hz}$.

Tab. 5. Vertical stiffness of main bearings of Sulzer 7 RTA 84 C engine

\begin{tabular}{|c|c|c|c|c|}
\hline $\begin{array}{c}\text { Main } \\
\text { Bearing } \\
\text { No. }\end{array}$ & $\begin{array}{c}\text { Stiffness } \\
\text { values } \\
\text { at } 0 \mathrm{~Hz} \\
\times \mathbf{1 0}^{9}[\mathrm{~N} / \mathrm{m}]\end{array}$ & $\begin{array}{l}\text { Stiffness } \\
\text { values } \\
\text { at } 8.33 \mathrm{~Hz} \\
\times 10^{9}[\mathrm{~N} / \mathrm{m}]\end{array}$ & $\begin{array}{c}\text { Stiffness } \\
\text { values } \\
\text { at } 11.67 \mathrm{~Hz} \\
\times 10^{9}[\mathrm{~N} / \mathrm{m}]\end{array}$ & $\begin{array}{c}\text { Stiffness } \\
\text { values } \\
\text { at } 25 \mathrm{~Hz} \\
\times \mathbf{1 0}^{9}[\mathrm{~N} / \mathrm{m}]\end{array}$ \\
\hline 1 & 6.632 & 6.611 & 6.591 & 6.442 \\
\hline 2 & 6.846 & 6.824 & 6.804 & 6.650 \\
\hline 3 & 7.335 & 7.321 & 7.308 & 7.203 \\
\hline 4 & 7.375 & 7.362 & 7.350 & 7.254 \\
\hline 5 & 7.382 & 7.370 & 7.357 & 7.264 \\
\hline 6 & 7.378 & 7.365 & 7.353 & 7.259 \\
\hline 7 & 7.348 & 7.334 & 7.321 & 7.219 \\
\hline 8 & 7.206 & 7.190 & 7.174 & 7.053 \\
\hline 9 & 6.327 & 6.301 & 6.274 & 6.309 \\
\hline
\end{tabular}

Tab. 6. Horizontal stiffness of main bearings of Sulzer 7 RTA 84 C engine

\begin{tabular}{|c|c|c|c|c|}
\hline $\begin{array}{c}\text { Main } \\
\text { bearing } \\
\mathbf{N o .}\end{array}$ & $\begin{array}{c}\text { Stiffness } \\
\text { values } \\
\text { at } \mathbf{0 ~ H z} \\
\left.\times \mathbf{1 0}^{\mathbf{9}} \mathbf{~} \mathbf{N} / \mathbf{m}\right]\end{array}$ & $\begin{array}{c}\text { Stiffness } \\
\text { values } \\
\text { at } \mathbf{8 . 3 3} \mathbf{~ H z} \\
\times \mathbf{1 0}^{\mathbf{9}}[\mathbf{N} / \mathbf{m}]\end{array}$ & $\begin{array}{c}\text { Stiffness } \\
\text { values } \\
\text { at } \mathbf{1 1 . 6 7} \mathbf{~ H z} \\
\times \mathbf{1 0}^{\mathbf{9}}[\mathbf{N} / \mathbf{m}]\end{array}$ & $\begin{array}{c}\text { Stiffness } \\
\text { values } \\
\text { at } \mathbf{2 5} \mathbf{~ H z} \\
\left.\times \mathbf{1 0}^{\mathbf{9}} \mathbf{~} \mathbf{N} / \mathbf{m}\right]\end{array}$ \\
\hline 1 & 10.969 & 10.924 & 10.878 & 10.447 \\
\hline 2 & 11.260 & 11.208 & 11.155 & 10.616 \\
\hline 3 & 12.260 & 12.195 & 12.128 & 11.406 \\
\hline 4 & 12.331 & 12.266 & 12.199 & 11.444 \\
\hline 5 & 12.356 & 12.290 & 12.222 & 11.435 \\
\hline 6 & 12.338 & 12.271 & 12.201 & 11.388 \\
\hline 7 & 12.279 & 12.210 & 12.138 & 11.303 \\
\hline 8 & 12.050 & 11.974 & 11.895 & 11.010 \\
\hline 9 & 9.714 & 9.643 & 9.572 & 8.847 \\
\hline
\end{tabular}


The sample plots (for the main bearing No.3) of displacement of main bearing foundation in function of vertical (and subsequently horizontal) frequency are presented in Fig.12. Selected fringe plots of the engine body deformation in the region of the main bearing No. 3 for excitations in both directions are shown in Fig.13.
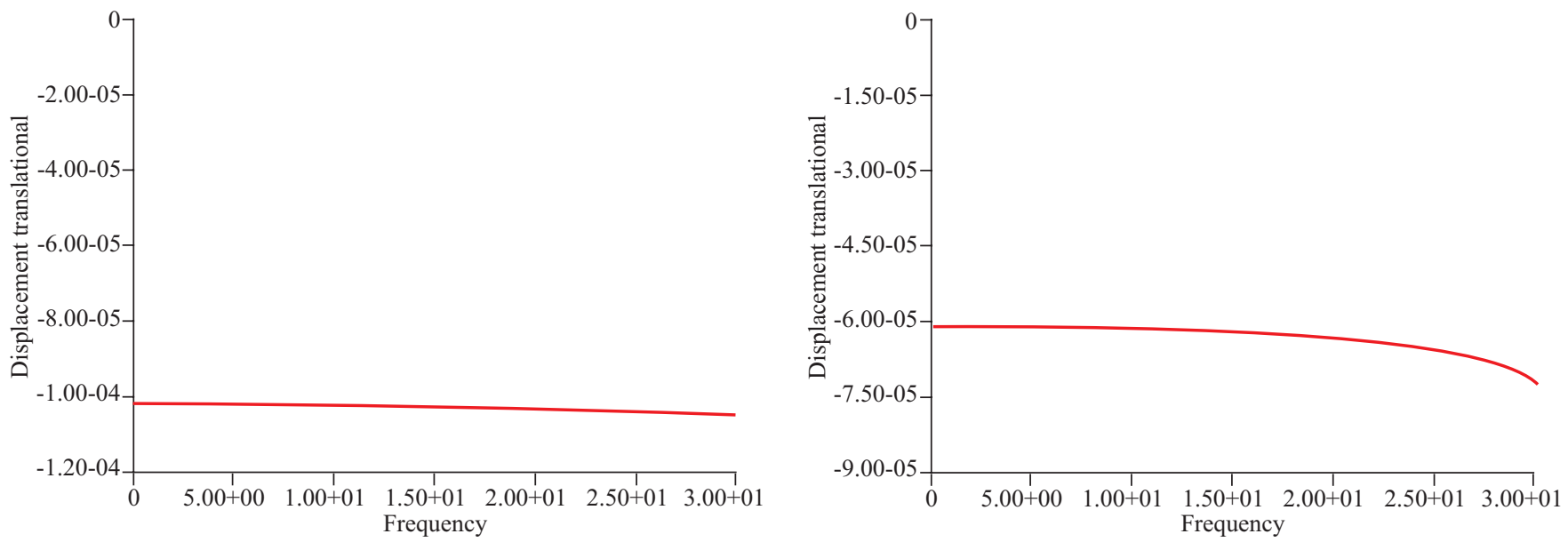

Fig. 12. Displacement of the main bearing No. 3 in function of excitation frequency .
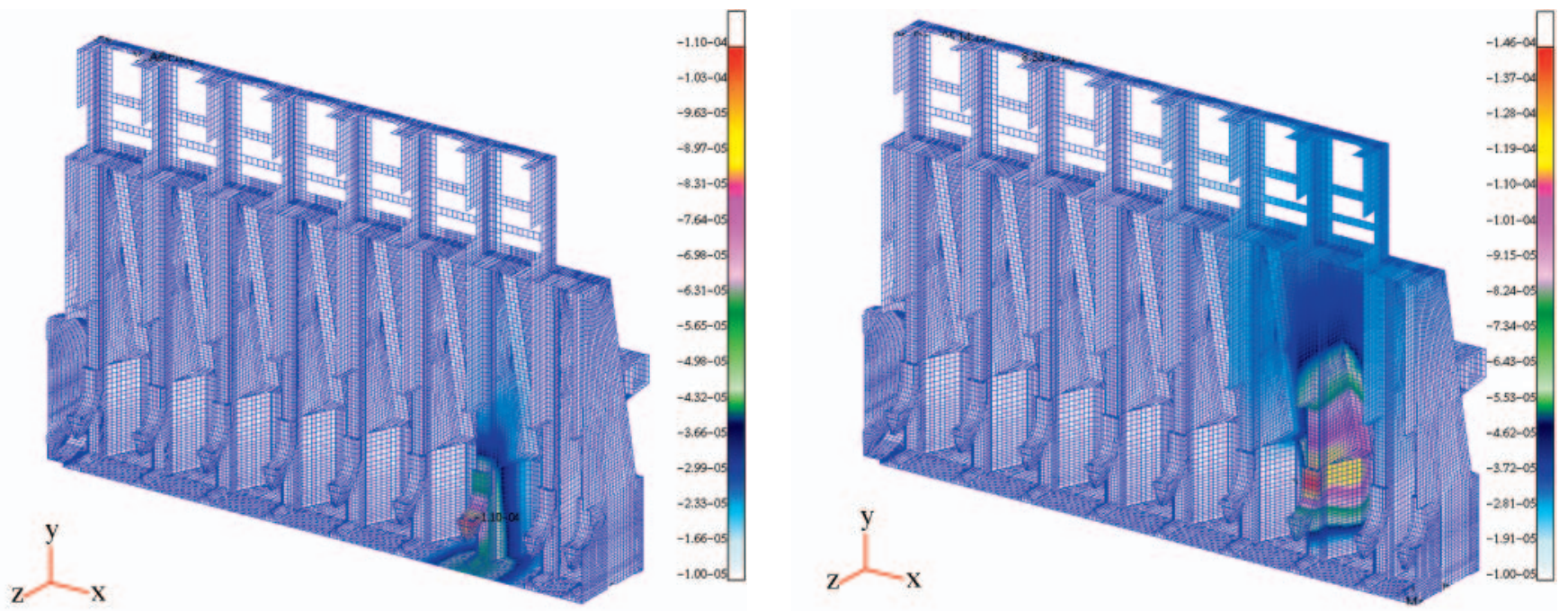

Fig. 13. Deformation of the main engine body under vertical and horizontal excitation applied to the main bearing No. 3. at the frequency of 8.33 Hz .

The dynamic stiffness values for the excitation frequency of $0 \mathrm{~Hz}$ are almost identical with the static stiffness (their differences are at $3^{\text {rd }}$ decimal place - see Tab. 4, 5 and 6). It speaks well for the correctness of the dynamic analysis. As it was expected after performance the analysis of normal modes, the dynamic stiffness values did not significantly differ from the static ones. The stiffness decrease by $2 \%$ in vertical direction may be observed and that in horizontal direction - by less than $7 \%$. Such change of dynamic stiffnesses can not have any significant effect on the analysis of shaft line lateral vibration. In standard (commercial) analyses the stiffness evaluation may be limited to only a static quantity which can be assumed constant in the domain of excitation frequency.

\section{CONCLUSIONS}

The numerically computed shaft line displacement is greater than that recommended by the producer despite the fact that the measured temperature of the real engine is slightly lower than its specified service temperature. For the first bearing (counting from the shaft line side) the difference is not particularly big (lower than $20 \%$ ), but other bearings are much more displaced. Hence the producer's assumption on the parallel translation of the crankshaft axis seems to be incorrect. The hogging deformation of the crankshaft results in a significant change of the moment load exerted by the shaft line. It may be expected that the effect resulting from the precise shaft line alignment analysis would be considerable.

On the basis of performed analysis it can be stated that the static stiffness values specified by the producer are properly evaluated, however they represent only the engine body flexibility without taking into account the ship's hull flexibility. In the shaft line alignment analysis the sum of both flexibility parameters should be taken into account. It can be observed that the engine's body stiffness is very high and the cylinder mass and gas forces acting on one cylinder have a little influence on displacements of other main bearings. Therefore it is not necessary to take into account any coupling between particular bearings.

It is important that the first significant normal modes have natural frequencies above the range of excitation frequencies of the propulsion system. Moreover the significant 
normal modes are few and those of interest concern the whole engine body. No significant normal modes were found in the region of the engine main bearings. It means that the engine body in question is a well-designed rigid structure. In such case the resonance discontinuities in the flexibility of main bearings should not be expected and their characteristics should be close to linear.

The dynamic stiffness values differ insignificantly from the static ones. The stiffness decrease by $2 \%$ can be observed in vertical direction and that by more than $7 \%$ in horizontal direction. Such change of dynamic stiffness values can not have any significant effect on results of the analysis of shaft line lateral vibration (whirling). In commercial analyses evaluation of stiffness may be limited only to determining the static value which - in the domain of excitation frequency - can be assumed constant.

The direction of research in question looks very promising. It would make it possible to introduce such improvements to high power propulsion systems as to avoid failures of the engine's main bearings. The presented method may be also used for more advanced and complete numerical computations carried out for main engines of other types, installed on ships having specific hulls.

The next step in developing the proposed method of propulsion system analysis should be incorporation of a more complex crankshaft representation based on its full 3D characteristics. The crankshaft springing effect on the shaft line alignment should be also examined.

\section{Acknowledgements}

The described project has been financed from the budget of Ministry of Science and Informatics, allocated to the Ship Design and Research Centre for its statutory activities in the year 2005. Execution of measurements on the real object and access to reliable engine's data were kindly made possible by Gdynia Shipyard Co. The authors are very grateful to all persons and institutions which supported this research project with really reliable data.

\section{NOMENCLATURE}

$\mathrm{dh}$ - thermal coefficient of expansion of the engine body $[\mathrm{mm} / \mathrm{K}]$

$\mathrm{h}_{\mathrm{e}}-$ vertical displacement of the main bearing axis [mm]

$\mathrm{h}$ - thermal heat transfer coefficient $\left[\mathrm{W} /\left(\mathrm{m}^{2} \mathrm{~K}\right)\right]$

$\mathrm{k}$ - thermal conduction coefficient $[\mathrm{W} /(\mathrm{mK})]$

$\mathrm{T}$ - temperature $[\mathrm{K}]$

$\mathrm{T}_{\mathrm{a}}$ - air temperature in the engine room $[\mathrm{K}]$

$\mathrm{T}_{\mathrm{s}}^{\mathrm{a}}$ - service temperature of the engine $[\mathrm{K}]$.

\section{BIBLIOGRAPHY}

1. MAN B\&W Diesel A/S : Bearings. Copenhagen. 2000

2. MAN B\&W Diesel A/S : Elasto-hydro-dynamic evaluation of main bearing performance. Copenhagen. 2002

3. American Bureau of Shipping: Guidance notes on propulsion shafting alignment. Houston. 2004

4. MAN B\&W Diesel A/S : Shafting alignment for direct coupled low-speed diesel propulsion plants. Copenhagen. 1995

5. Wärtsilä: Sulzer RTA-C. Technology Review, Helsinki. 2003.

\section{CONTACT WITH THE AUTHORS}

Lech Murawski, D.Sc., M.E.

Marek Szmyt, M.Sc., M.E.

Centrum Techniki Okrętowej S. A.

Rzeczypospolitej 8

80-369 Gdańsk, POLAND

e-mail : Lech.Murawski@cto.gda.pl

\section{Mourning}

9 August 2006 was the time of a deep sorrow for the circle of Polish shipbuilders as

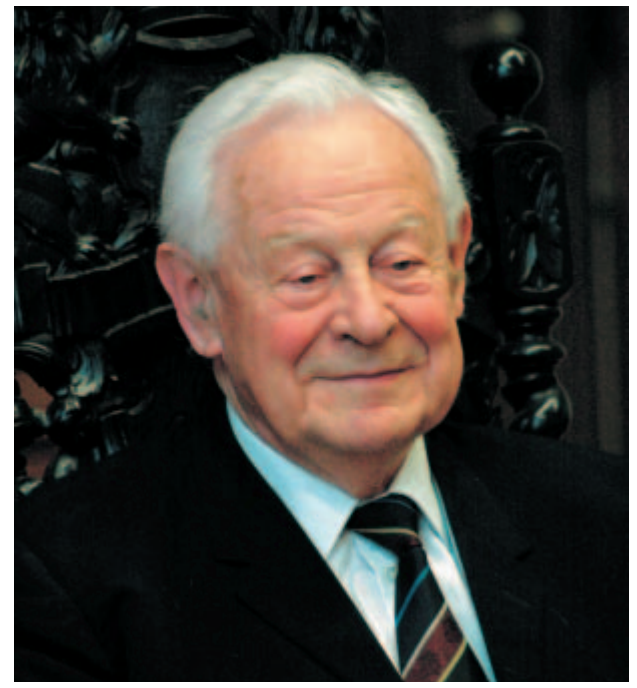

Professor Jerzy Doerffer

passed away this day.

Graduate of Shipbuilding Faculty of University of Glasgow and Gdańsk University of Technology.

Professor of Gdańsk University of Technology where he worked since 1948.

The organizer and the first Head of the Department of Ship Technology and its auxiliary unit.

The Dean of Shipbuilding Faculty

in the years 1953-54 and 1958-64.

The Rector of Gdańsk University of Technology in the years 1964-67.

The Chairman of the Forum of Shipbuilding and Ship Repair Industry.

The creator of the scientific school in the domain of shipbuilding technology.

He was a worldwide recognized authority on this domain.

The co-author of novel design solutions and manufacturing techniques in ship technology.

Doctor Honoris Causa of Gdańsk University of Technology, Leningrad Shipbuilding Institute, University of Glasgow, University of Rostock, Polish Naval University and Technical University of Szczecin.

He was also honoured with William Froude Medal by the Royal Institution of Naval Architects, London.

Prof. Doerffer was not only an outstanding engineer-inventor but also a moral authority of wonderful personality. Due to his attitude and work he won respect from the side of the whole circle of Polish shipbuilders.

He was a figure-symbol of whom the circle of Polish shipbuilders boasts.

Humanist and teacher. He promoted a whole generation of Polish engineers in shipbuilding technology.

A member of prestigious scientific institutions in Poland and in the world. 